\title{
Retroperitoneal Smooth Muscle Tumor of Uncertain Malignant Potential (STUMP): Case Report
}

\section{Moussa Sylla*, Pierlesky Elion Ossibi, Issam Yazough, Eddy Oleko Ekuke, El Bachir Benjelloun, Said Ait Laalim, Khalid Mazaz, Khalid Ait Taleb}

Visceral Surgery Department, Hassan II University Hospital, Fez, Morocco

Email: *syllams86@yahoo.fr

How to cite this paper: Sylla, M., Ossibi, P.E., Yazough, I., Ekuke, E.O., Benjelloun, E.B., Laalim, S.A., Mazaz, K. and Taleb, K.A. (2016) Retroperitoneal Smooth Muscle Tumor of Uncertain Malignant Potential (STUMP): Case Report. Surgical Science, 7, 528-531.

http://dx.doi.org/10.4236/ss.2016.712070

Received: July 22, 2016

Accepted: December 18, 2016

Published: December 21, 2016

Copyright $\odot 2016$ by authors and Scientific Research Publishing Inc. This work is licensed under the Creative Commons Attribution International License (CC BY 4.0).

http://creativecommons.org/licenses/by/4.0/

(c) (i) Open Access

\begin{abstract}
Retro peritoneal smooth muscle tumors of uncertain malignant potential (STUMP) are rare and often misdiagnosed as leiomyosarcoma. We hereby report the case of a retroperitoneal STUMP diagnosed on a surgical specimen in a 44-year-old woman without any history of disease.
\end{abstract}

\section{Keywords}

Smooth Muscle Tumors, Uncertain Malignant Potential, Retroperitoneal

\section{Introduction}

The general term "Smooth muscle Tumors of Uncertain Malignant Potential" (STUMP) represents a broad spectrum of mesenchymal tumors whose definition, classification and prognosis remain a subject of controversy [1]. The most common locations reported in the literature are uterine [2], rarely prostate [3] and sometimes vulvo-vaginal [4]. Primary retroperitoneal location is rare. A recent case of a secondary location of retro peritoneal uterine STUMP was reported in 2012 in Korea [5]. We report the case of a 44-year-old woman without significant history who was admitted to our unit for an abdominal mass and whose histological examination of surgical specimen came back for a retro peritoneal smooth muscle tumor of uncertain malignant potential (STUMP).

\section{Case Report}

Patient, 44-year-old female, single, nulligeste, nulliparous without any notable 
clinical history presented with a 10 month history of abdominal bulging without any associated signs.

Physical examination found a distended abdomen with a large abdominal pelvic mass.

Abdomino pelvic ultrasound revealed a tissular mass of the right ovary, highly vascularised on Doppler coding.

CT confirmed an enormous cystic mass with three components: solid mass, predominantly cystic and containing calcifications; with abundant ascites (Figure 1(a) and Figure 1(b)). Ovaries and uterus were unremarkable. Neither peritoneal carcinomatosis nor lung nor liver metastases were observed.

Case was presented at a multidisciplinary oncology meeting where exploratory surgery was indicated.

A distended uterus bearing a $40 \mathrm{~cm}$ fundal mass generally smooth in nature with a whitish outer layer adjacent to a retroperitoneal mass measuring $50 \mathrm{~cm}$ extending up to the xiphoid process with a smooth outer lining without any vegetations or exo-cystic granulations were discovered per operatively (Figure 2). Fallopian tubes and ovaries were without any sign of malignancy. However several small bowel loops were in some parts joined to the uterine mass. Portions of

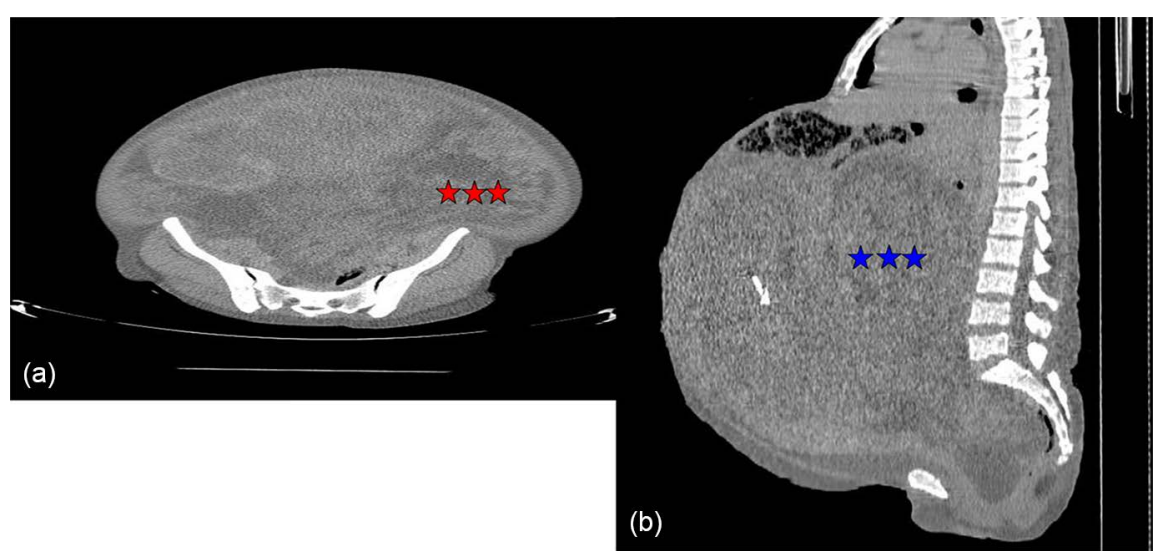

Figure 1. (a) Transverse section showing the retroperitoneal mass $(\star \star \star)$; (b) Sagittal cross section showing the retroperitoneal mass $(\star \star \star)$.

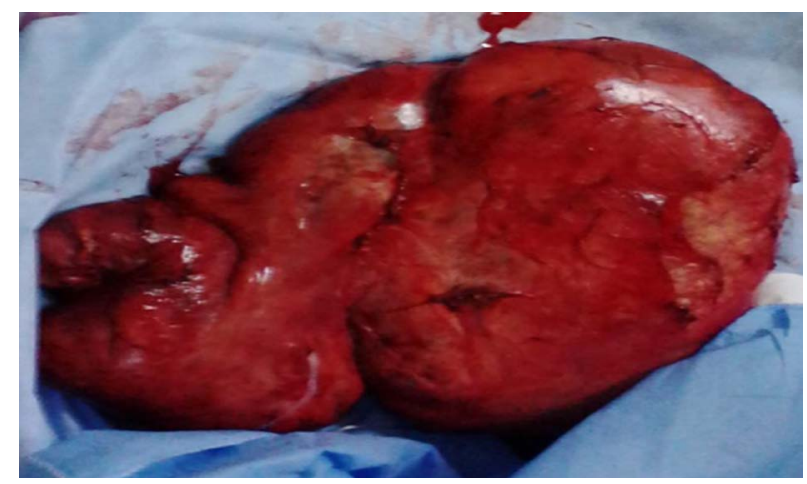

Figure 2. Operative specimen of retroperitoneal mass. 
the ascending colon and descending colons as well as segments of small intestine were attached to the retroperitoneal mass in close contact with the transverse mesocolon.

Management consisted of a total hysterectomy with bilateral oophorectomy and resection of retroperitoneal mass whiles preserving the digestive tract.

Pathology examination of surgical specimens returned for:

- Smooth muscle tumor of uncertain malignant potential (STUMP) for the retroperitoneal mass,

- Leiomyoma in aseptic necrobiosis for hysterectomy specimen with no underlying malignancy,

- Fallopian tubes and ovaries were without malignancies.

The case was discussed again at a multidisciplinary meeting where a decision to closely monitor the patient was made.

Post operative recovery was uneventful and outcome was favorable without local recurrence to till date.

\section{Discussion}

Primitive retroperitoneal tumors are rare in adults. They represent a heterogeneous group of lesions most often malignant (80\%) than benign (20\%). Primitive retroperitoneal tumors (PRT) in adults are rare, and for most lesions malignant. Prevalence is less than $1 \%$ of tumors. STUMPs are very rare and poorly documented in literature [6]. Diagnosis often made in patients aged between 40 and 50 years [7] as was the case in our patient. Discovery is often late after extensive tumor growth, owing to the apparent good compliance of the retro peritoneal space in which they develop [7] as was the case in our patient. Computed tomography (CT) and magnetic resonance imaging (MRI) are the best imaging tools in the diagnosis and monitoring of PRT [6]. These imaging technics provide enhanced density resolution or signal intensity clarity allowing for positive diagnosis of the nature of the lesion. They may reveal associated signs pointing to a number of etiologies. Ultrasound can also highlight these tumors, but remains largely hindered by the large size of these lesions and it does not allow the determination of tumor origin and links with adjacent organs. Surgery remains the main curative treatment and entails a complete resection of the tumor with or without adjuvant radiation therapy [4]. As far as pathology is concerned, they are characterized by: minimally atypical smooth muscle neoplasms with a low mitotic index with uncertainty surrounding their nature (standard vs. myxoid, epithelioid vs. gold standard); combination of standard smooth muscle differentiation, marked diffuse severe atypia, low mitotic index and uncertainty about whether coagulative tumor cell necrosis is present; moderate to severe atypia plus uncertain mitotic index because possible mitotic figures may be degenerating nuclei mimicking mitotic figures [8]. The place of adjuvant radio chemotherapy is yet to be defined in the management of such tumors. Close monitoring of 
patients is recommended with regular check-ups every 3 months and follow up imaging in case of possible recurrence.

\section{Conclusion}

Smooth muscle tumors of uncertain malignant potential (STUMP) are rare with retroperitoneal location being exceptional. Only pathology can ascertain that their diagnosis and treatment is surgical.

\section{References}

[1] Herawi, M. and Epstein, J.I. (2006) Specialized Stromal Tumors of the Prostate: A Clinicopathologic Study of 50 Cases. The American Journal of Surgical Pathology, 30, 694-704. https://doi.org/10.1097/00000478-200606000-00004

[2] Ip, P.P., Cheung, A.N. and Clement, P.B. (2009) Uterine Smooth Muscle Tumors of Uncertain Malignant Potential (STUMP): A Clinicopathologic Analysis of 16 Cases. The American Journal of Surgical Pathology, 33, 992-1005. https://doi.org/10.1097/PAS.0b013e3181a02d1c

[3] Michaud, S., Moreau, A., Braud, G., Renaudin, K., Branchereau, J., Bouchot, O. and Rigaud, J. (2012) Tumeur stromale prostatique à potentiel malin incertain (STUMP): Définition, anatomopathologie, pronostic et prise en charge. Progrès en urologie, 22, 688-691. https://doi.org/10.1016/j.purol.2012.06.004

[4] Ozcan, A., Toz, E., Cakir, I.E., Karadeniz, T., Kahraman, D.S., Vural, T. and Sanci, M. (2016) Smooth-Muscle Tumor of Vulva with Uncertain Malignant Potential: A Case Report. Case Reports in Obstetrics and Gynecology, 3, 68-71.

[5] Jung, M.-J., Park, J.H., Choi, S.-J., Song, E.S., Hwang, S.O. and Park, J.-W. (2012) Retroperitoneal Recurrence of Uterine Smooth Muscle Tumor of Uncertain Malignant Potential as Leiomyosarcoma. Korean Journal of Obstetrics and Gynecology, 55, 996-1000. https://doi.org/10.5468/KJOG.2012.55.12.996

[6] Merran, S., Karila-Cohen, P. and Vieillefond, A. (2004) Primary Retroperitoneal Tumors in Adults. Journal de Radiologie, 85, 252-264. https://doi.org/10.1016/S0221-0363(04)97576-2

[7] Mizuki, N., Hayakawa, K., Minami, M., et al. (2003) Primary Retroperitoneal Neoplasms: CT and MR Imaging Findings with Anatomic and Pathologic Diagnostic Clues. RadioGraphics, 23, 45-57. https://doi.org/10.1148/rg.231025037

[8] Kempson, R.L. and Hendrickson, M.R. (2000) Smooth Muscle, Endometrial Stromal, and mixed Müllerian Tumors of the Uterus. Modern Pathology, 13, 328-342. https://doi.org/10.1038/modpathol.3880055 
Submit or recommend next manuscript to SCIRP and we will provide best service for you:

Accepting pre-submission inquiries through Email, Facebook, LinkedIn, Twitter, etc. A wide selection of journals (inclusive of 9 subjects, more than 200 journals)

Providing 24-hour high-quality service

User-friendly online submission system

Fair and swift peer-review system

Efficient typesetting and proofreading procedure

Display of the result of downloads and visits, as well as the number of cited articles

Maximum dissemination of your research work

Submit your manuscript at: http://papersubmission.scirp.org/

Or contact ss@scirp.org 